\title{
Bypass Diode Temperature Tests of a Solar Array Coupon under Space Thermal Environment Conditions
}

\author{
Kenneth H. Wright Jr. ${ }^{1}$, Todd A. Schneider ${ }^{2}$, Jason A. Vaughn ${ }^{2}$, Bao Hoang ${ }^{3}$, Frankie Wong ${ }^{3}$, and \\ Gordon $\mathrm{Wu}^{3}$ \\ ${ }^{1}$ University of Alabama Huntsville, Huntsville, AL 35899, ${ }^{2}$ NASA/MSFC, Huntsville, AL, 35812, USA, \\ ${ }^{3}$ Space Systems Loral, LLC, Palo Alto, CA, 94303, USA
}

\begin{abstract}
Tests were performed on a 56-cell Advanced Triple Junction solar array coupon whose purpose was to determine margin available for bypass diodes integrated with new, large multi-junction solar cells that are manufactured from a 4 -inch wafer. The tests were performed under high vacuum with coupon back side thermal conditions of both cold and ambient. The bypass diodes were subjected to a sequence of increasing discrete current steps from $0 \mathrm{Amp}$ to $2.0 \mathrm{Amp}$ in steps of 0.25 Amp. At each current step, a temperature measurement was obtained via remote viewing by an infrared camera. This paper discusses the experimental methodology, experiment results, and the thermal model.
\end{abstract}

Index Terms - bypass diodes, infrared imaging, solar cell testing, thermal modeling.

\section{INTRODUCTION}

Bypass diodes are a key design feature of photovoltaic array systems by allowing a string to function in the event of a shadow on the string or in spite of failure of one or more cells in the string [1]. The location and thermal boundary condition of bypass diodes in the system architecture dictates that sufficient margin in current must exist such that, when in operation, local heating does not cause damage to the bypass diode, the solar cell or its material surroundings. The design of bypass diodes within the array should not be overlooked.

The NASA Marshall Space Flight Center (MSFC) performed thermal testing on a 56-cell Advanced Triple Junction solar array coupon provided by Space Systems/Loral, LLC (SSL). The purpose of this test was to obtain results for input to thermal model development. This model could be exploited to determine the margin available for new, large multi-junction solar cells that are manufactured from a 4-inch wafer. The tests were performed under high vacuum with the coupon back-side colder than the coupon front-side, and also with coupon back-side at ambient temperature. Back-side cooling was accomplished via direct thermal contact to a cold plate serviced with liquid nitrogen. Thermocouples were mounted on both the coupon front and back to monitor the temperature gradient through the coupon. The bypass diodes were subjected to a sequence of increasing discrete current steps of $0.25 \mathrm{~A}$ from $0 \mathrm{~A}$ to $2.0 \mathrm{~A}$. At each current step, the diodes were allowed to thermally stabilize before a temperature measurement was obtained via remote viewing by an infrared (IR) camera mounted exterior to the vacuum chamber. This paper discusses the experimental methodology, including the calibration of the thermal imaging system, and the results.

\section{EXPERIMENT SETUP}

The coupon was mounted in a vacuum chamber that has the following approximate dimensions: $1 \mathrm{~m}$ diameter and $2 \mathrm{~m}$ length. Vacuum is achieved via oil-free pumping with scroll pump for roughing and cryogenic pumps for high vacuum. Base pressure achieved for testing was in the $10^{-5} \mathrm{~Pa}\left(10^{-7}\right.$ Torr) range.

The coupon was inserted with its long axis parallel to the chamber axis and the front side facing the view port for IR camera viewing. Fig. 1 shows a picture of the coupon installed in the chamber. A cold plate of approximately the same area as the coupon was located immediately behind the coupon. The cold plate was cooled with liquid nitrogen $\left(\mathrm{LN}_{2}\right)$. Three tests were performed. In Test 1 , there was a gap between the coupon backside and the cold plate surface of $\sim 3.8 \mathrm{~cm}$. For Test 2 and Test 3, the coupon backside was in direct contact with the cold plate. In Test $2, \mathrm{LN}_{2}$ was used in the cold plate while in Test 3 no $\mathrm{LN}_{2}$ was used. Thermocouples were mounted on the front and back surfaces of the coupon.

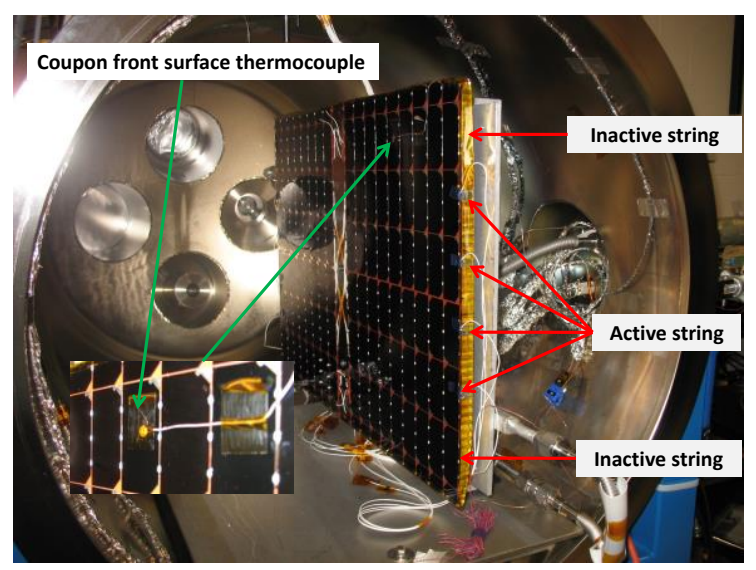

Fig. 1. Solar Array Coupon mounted in the vacuum chamber. 


\section{A. Calibration of Thermal Image System}

The infrared (IR) camera used in this test was a FLIR SC655 IR Camera. Calibration of the camera needed to be performed with the same optics as that used in the test. The setup is shown in Fig. 2. A calibrated Mikron M340 blackbody source was chosen to represent a known temperature reference. The Mikron M340 has a range of $-20 \mathrm{C}$ to $150 \mathrm{C}$ and has active cooling so that equilibrium times are short for scanning in both directions. A coverglass, like that used on the coupon, was placed over the entrance to the blackbody cavity. The ZnSe viewport was located at $\sim 58$ $\mathrm{cm}$ (22.9 inch) above the coverglass. This distance is the same as that realized in the chamber setup shown in Fig. 1. The IR camera was located $\leq 2.5 \mathrm{~cm}(1 \mathrm{inch})$ from the $\mathrm{ZnSe}$ surface.

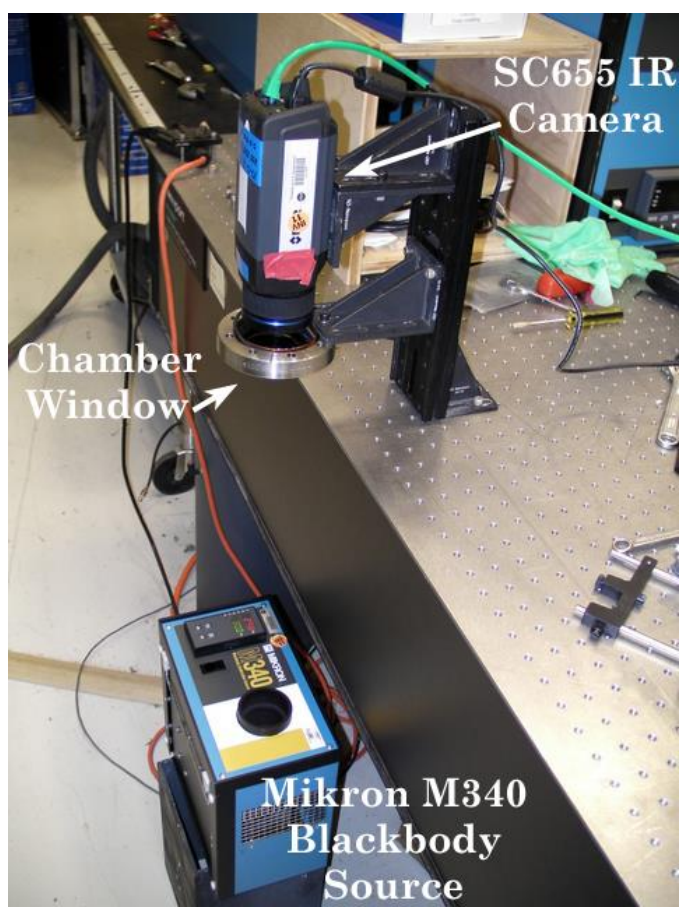

Fig. 2. Photo of the IR camera, window, and blackbody source configured for calibration in the lab.

Calibration data was recorded from two separate regions of the camera detector array, one from within the image of the coverglass and one from a portion of the image of the emissive surface unobstructed by the coverglass. Data was obtained over a temperature range from $0 \mathrm{C}$ to $150 \mathrm{C}$ in steps of $10 \mathrm{C}$.

\section{TEST RESUlTS}

A test limit of $150 \mathrm{C}$ on any diode or any part of the coupon was set by SSL in order to prevent possible damage to the coupon. Test 1 was conducted using this temperature limit. However, for Test 2 and Test 3 this temperature limit was waived in order to maximize data acquisition for the thermal model development. At each diode current step, the current flowed through the diodes for 15 minutes to allow for thermal equilibrium. During all tests, all ports, except for the IR camera viewing port, were covered to prevent any stray light inside chamber. Results from each test are shown in the following sections.

\section{A. Test 1}

For Test 1, there was a gap between the coupon backside and the cold plate surface of $\sim 3.8 \mathrm{~cm}$. The base pressure reached before application of diode currents was $4 \times 10^{-5} \mathrm{~Pa}$. $\mathrm{LN}_{2}$ flowed through cold plate during the entire test and the cold plate temperature was maintained at $-180 \mathrm{C}+/-2 \mathrm{C}$. Table I shows the maximum temperature observed by the IR camera at each current step. At first, the IR camera was tuned to the single diodes. However, the double diodes were realized to be hotter and the IR camera was tuned to the double diodes. The maximum TC temperatures reached were front at $49 \mathrm{C}$ and the rear at $68 \mathrm{C}$. Fig. 3 shows the time history of each TC. Fig. 4 shows the IR camera image with the distribution of temperature on the coupon.

TABLE I. Test 1 Diode Temperature

\begin{tabular}{|c|c|}
\hline $\begin{array}{c}\text { Bypass } \\
\text { Diode } \\
\text { Current } \\
\text { (A) }\end{array}$ & $\begin{array}{c}\text { Max IR } \\
\text { Temperature } \\
\text { (C) } \\
\text { S = Single } \\
\text { D = Double }\end{array}$ \\
\hline 0.0 & $18(\mathrm{~S})$ \\
\hline 0.25 & $26(\mathrm{~S})$ \\
\hline 0.50 & $56(\mathrm{D})$ \\
\hline 0.75 & $85(\mathrm{D})$ \\
\hline 1.00 & $116(\mathrm{D})$ \\
\hline 1.25 & $148(\mathrm{D})$ \\
\hline
\end{tabular}

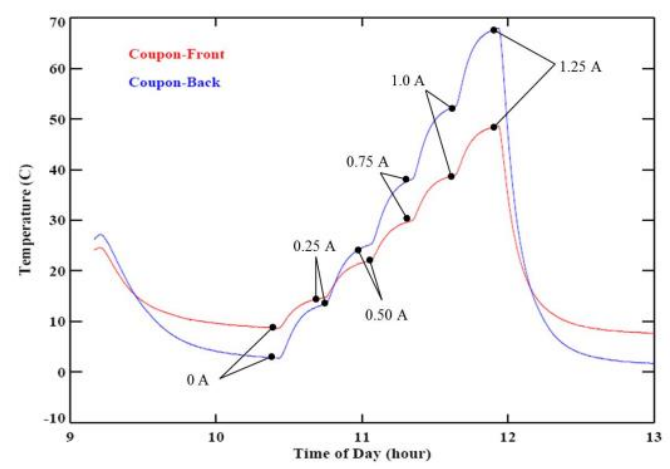

Fig. 3. Temperature history of thermocouples for Test 1. Diode current is noted in figure. 


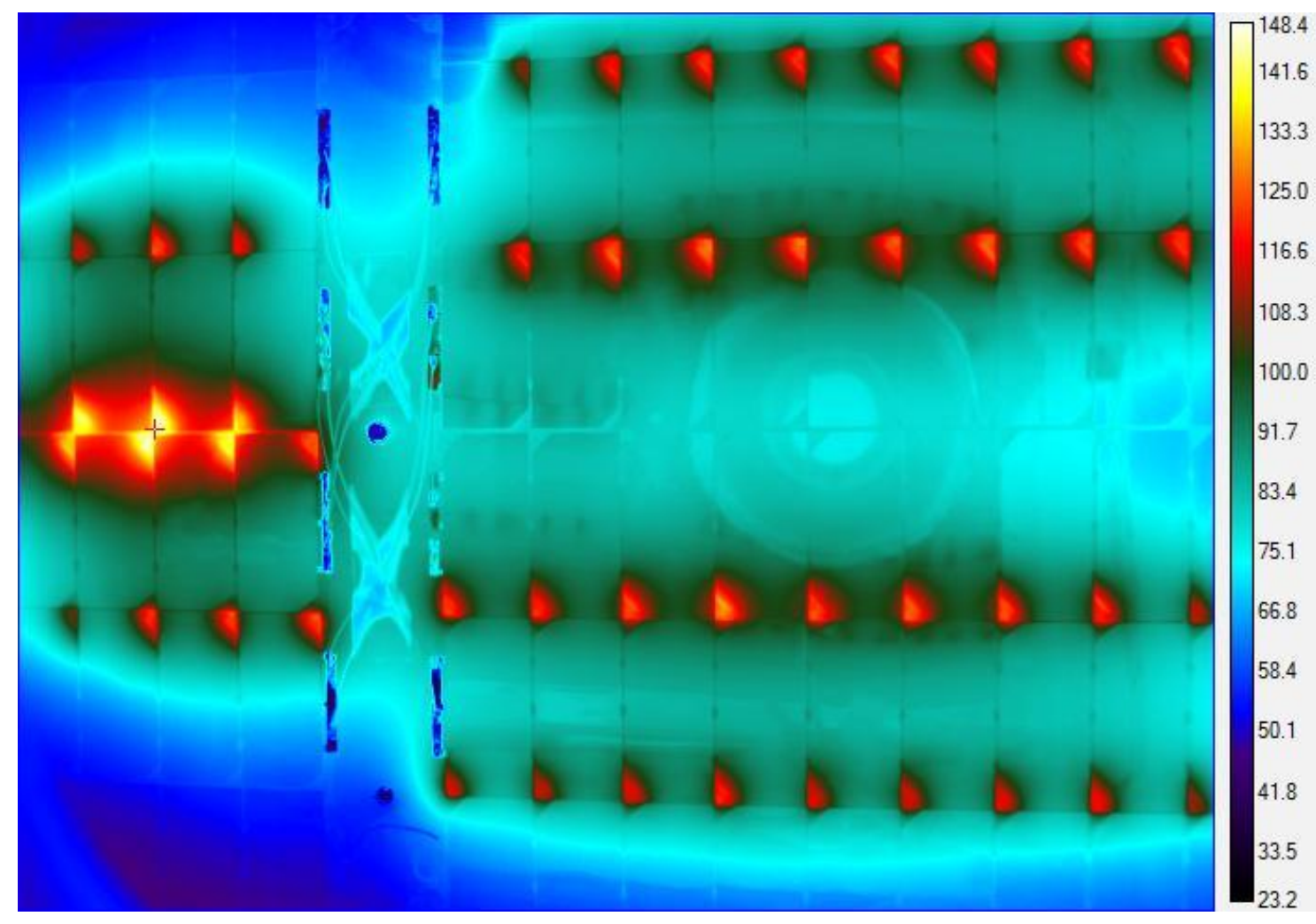

Fig. 4. IR camera image for the 1.25 A case of Test 1. Color bar is in units of C.

\section{B. Test 2}

For Test 2, the coupon was placed in direct contact with the cold plate. A sheet of Kapton XC (black in color, electrically conductive Kapton) was inserted between the cold plate and coupon backside surfaces to promote thermal conduction. $\mathrm{LN}_{2}$ flowed through cold plate during the entire test and the cold plate temperature was maintained at $-180 \mathrm{C}+/-2 \mathrm{C}$. The chamber pressure was $1.0 \times 10^{-4} \mathrm{~Pa}\left(7.8 \times 10^{-7}\right.$ Torr $)$. The upper limit of current for this test was set at $2.0 \mathrm{~A}$ - two times the nominal design current of 1.0 A.
Table II shows the maximum temperature observed by the IR camera at each current step. The maximum TC temperatures reached were front at $85 \mathrm{C}$ and the rear at $35 \mathrm{C}$. Fig. 5 shows the time history of each TC. Fig. 6 shows the IR camera image with the distribution of temperature on the coupon. 
TABLE II. Test 2 Diode Temperature

\begin{tabular}{|c|c|c|}
\hline \multirow{2}{*}{$\begin{array}{c}\text { Bypass } \\
\text { Diode } \\
\text { Current } \\
(\mathbf{A})\end{array}$} & \multicolumn{2}{|c|}{ Max IR Temperature (C) } \\
\cline { 2 - 3 } & Single & Double \\
\hline 0.0 & 5 & 6 \\
\hline 0.25 & 22 & 26 \\
\hline 0.50 & 46 & 56 \\
\hline 0.75 & 72 & 86 \\
\hline 1.00 & 99 & 117 \\
\hline 1.25 & 126 & 146 \\
\hline 1.50 & 158 & 178 \\
\hline 1.75 & 201 & 206 \\
\hline 2.00 & 252 & 255 \\
\hline
\end{tabular}

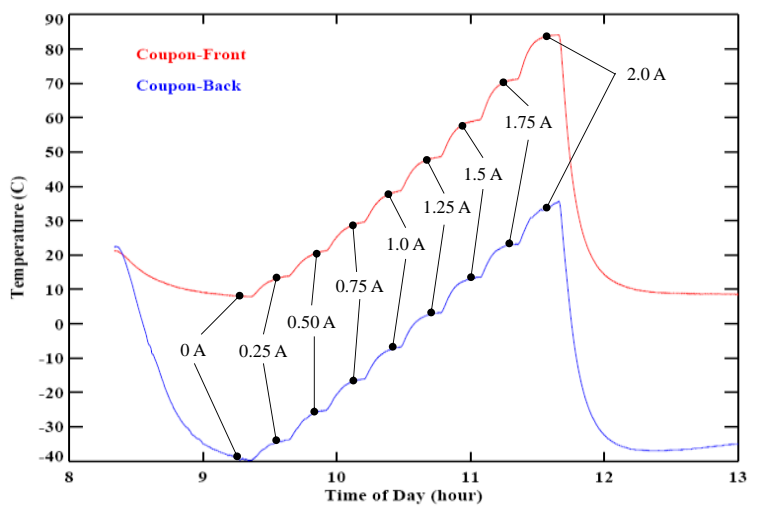

Fig. 5. Temperature history of thermocouples for Test 2. Diode current is noted in figure.

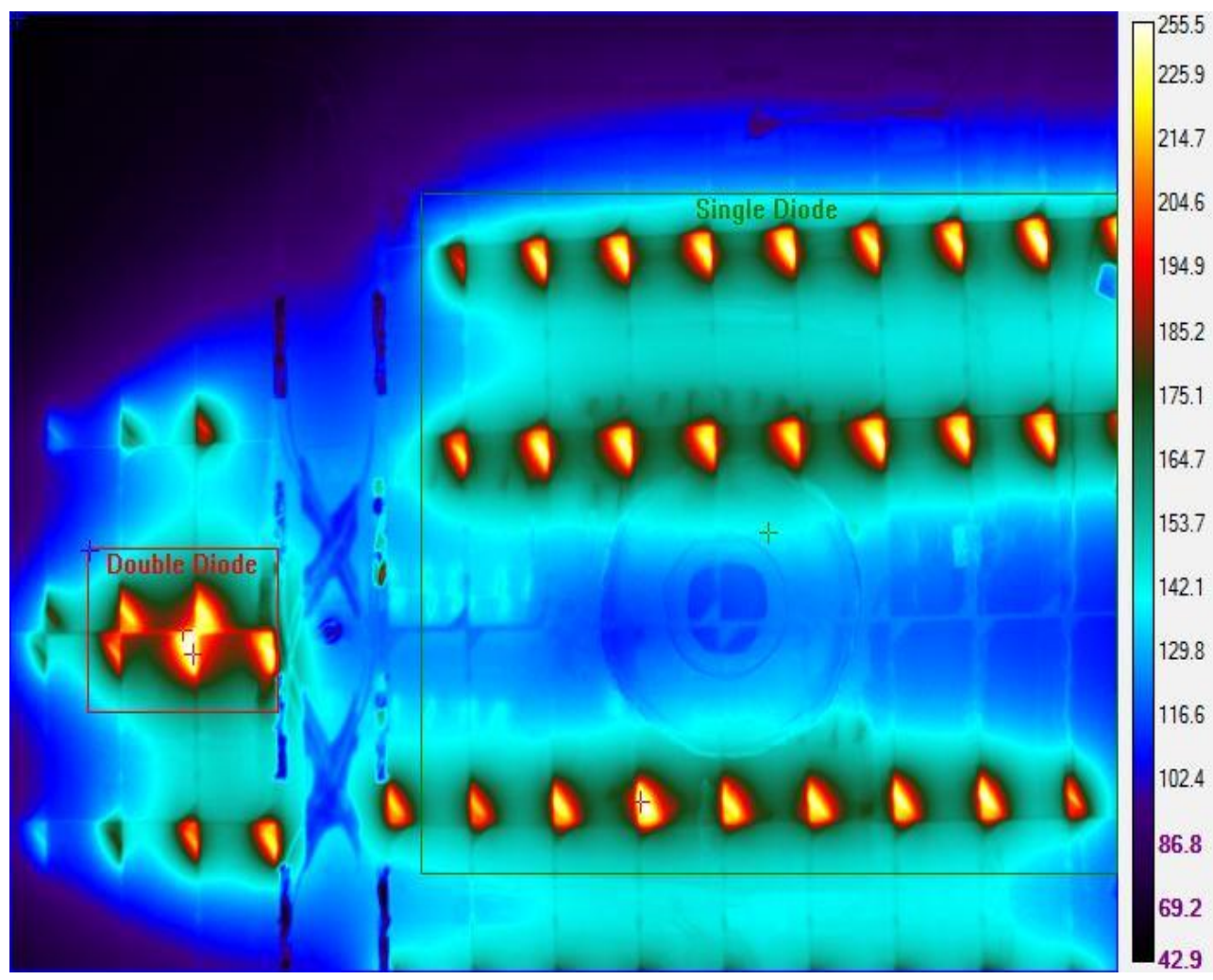

Fig. 6. IR camera image for the 2.0 A case of Test 2. Color bar is in units of C. 


\section{B. Test 3}

The coupon is in same configuration as Test \#2 - coupon rear surface in direct contact with cold plate. However, for this test no LN2 was used - the cold plate at ambient temperature. Test 3 stopped after the $1.5 \mathrm{~A}$ condition per instruction from SSL because the single diode location showed a temperature of near $180 \mathrm{C}$. Table III shows the maximum temperature observed by the IR camera at each current step. The maximum TC temperatures reached were front at $68 \mathrm{C}$ and the rear at $67 \mathrm{C}$. Fig. 7 shows the time history of each TC. Fig. 8 shows the IR camera image with the distribution of temperature on the coupon.

TABLE III. Test 3 Diode Temperature

\begin{tabular}{|c|c|c|}
\hline \multirow{2}{*}{$\begin{array}{c}\text { Bypass } \\
\text { Diode } \\
\text { Current } \\
(\mathbf{A})\end{array}$} & \multicolumn{2}{|c|}{ Max IR Temperature (C) } \\
\cline { 2 - 3 } & Single & Double \\
\hline 0.0 & 21 & 21 \\
\hline 0.25 & 40 & 44 \\
\hline 0.50 & 62 & 70 \\
\hline 0.75 & 84 & 97 \\
\hline 1.00 & 110 & 127 \\
\hline 1.25 & 141 & 166 \\
\hline 1.50 & 178 & 210 \\
\hline
\end{tabular}

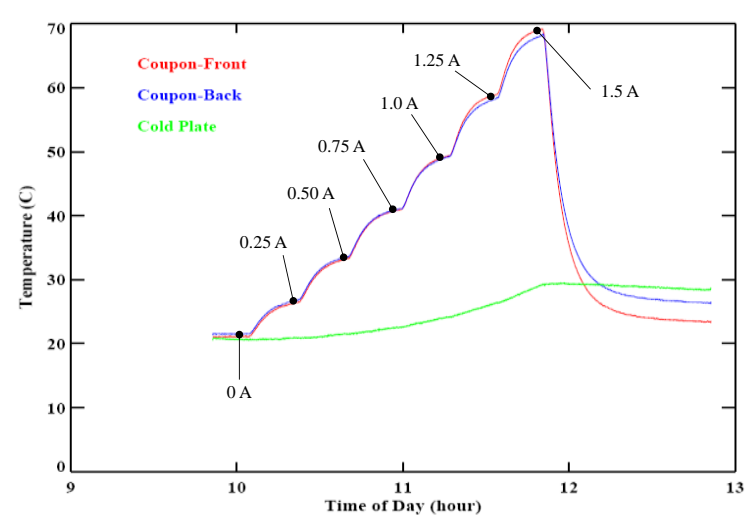

Fig. 7. Temperature history of thermocouples for Test 3. Diode current is noted in figure.

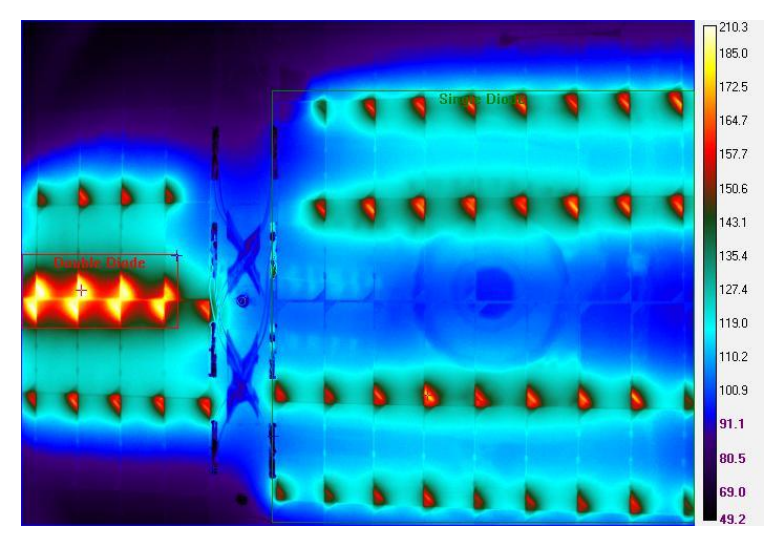

Fig. 8. IR camera image for the $1.50 \mathrm{~A}$ case of Test 3. Color bar is in units of $\mathrm{C}$.

\section{SSL THERMAL MODEL}

The MSFC test results were used to correlate with SSL thermal model analysis and to determine limits of array designs with larger solar cells. The coupon backside in the model faces deep space $(-270 \mathrm{C})$. The model was run with various front-side thermal load conditions for two cell sizes: $30.5 \mathrm{~cm}^{2}$ and $58.3 \mathrm{~cm}^{2}$. The ATJ cells used in the MSFC test are the $30.5 \mathrm{~cm}^{2}$ cell. Table IV and Fig. 9 shows bypass diode temperatures for the $30.5 \mathrm{~cm}^{2}$ cell case. Table V and Fig. 10 shows bypass diode temperatures for the $58.2 \mathrm{~cm}^{2}$ cell case.

TABLE IV. Diode Temperature in $\mathrm{C}$ for $30.5 \mathrm{~cm}^{2}$ cell

\begin{tabular}{|c|c|c|c|c|}
\hline \multirow{2}{*}{$\begin{array}{c}\text { Thermal } \\
\text { Load }\end{array}$} & \multicolumn{4}{|c|}{ Diode Current } \\
\cline { 2 - 5 } & $0.5 \mathrm{~A}$ & $1.0 \mathrm{~A}$ & $1.25 \mathrm{~A}$ & $1.5 \mathrm{~A}$ \\
\hline No Sun & -42.4 & 36.8 & 73 & 95.7 \\
\hline $0.25 \mathrm{Sun}$ & 21 & 77 & 106.5 & 125.3 \\
\hline 0.5 Sun & 58.1 & 105.3 & 131.4 & 148 \\
\hline 0.75 Sun & 85.9 & 127.9 & 151.7 & 166.8 \\
\hline 1 Sun & 108.7 & 146.9 & 169.1 & 183 \\
\hline Ambient & 57.3 & 104 & 129.9 & 146.5 \\
\hline
\end{tabular}




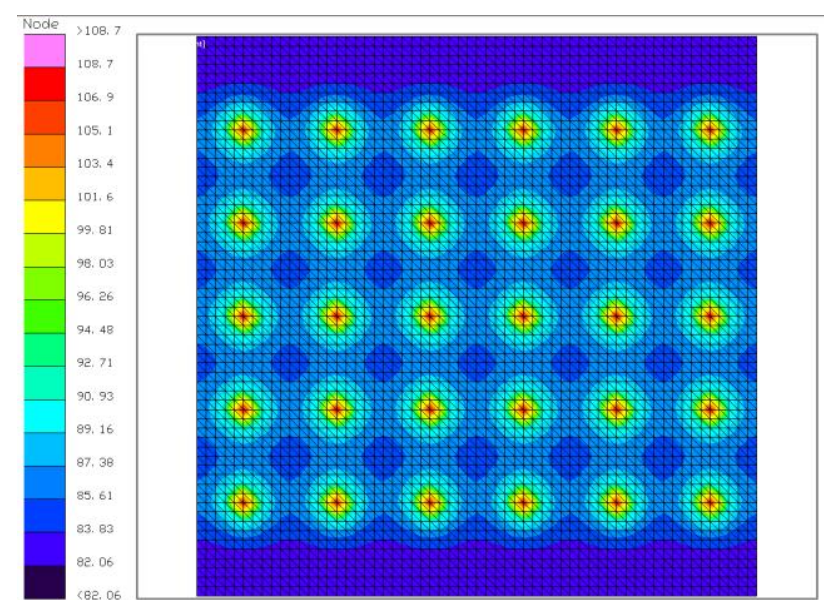

Fig. 9. Temperature distribution for 1 sun illumination on front-side and diode current $=0.5 \mathrm{~A}$ for the $30.5 \mathrm{~cm}^{2}$ cell. Color bar is in units of $\mathrm{C}$.

TABLE V. Diode Temperatures in $\mathrm{C}$ for $58.3 \mathrm{~cm}^{2}$ cell

\begin{tabular}{|c|c|c|c|}
\hline \multirow{2}{*}{$\begin{array}{c}\text { Thermal } \\
\text { Load }\end{array}$} & \multicolumn{3}{|c|}{ Diode Current } \\
\cline { 2 - 4 } & $1.0 \mathrm{~A}$ & $1.25 \mathrm{~A}$ & $1.5 \mathrm{~A}$ \\
\hline No Sun & 24.8 & 62.0 & 85.4 \\
\hline 0.25 Sun & 72.6 & 101.8 & 120.6 \\
\hline 0.5 Sun & 103.0 & 128.8 & 145.3 \\
\hline 0.75 Sun & 126.5 & 150.0 & 165.0 \\
\hline 1 Sun & 146.0 & 168.0 & 181.8 \\
\hline Ambient & 101.9 & 127.5 & 144.0 \\
\hline
\end{tabular}

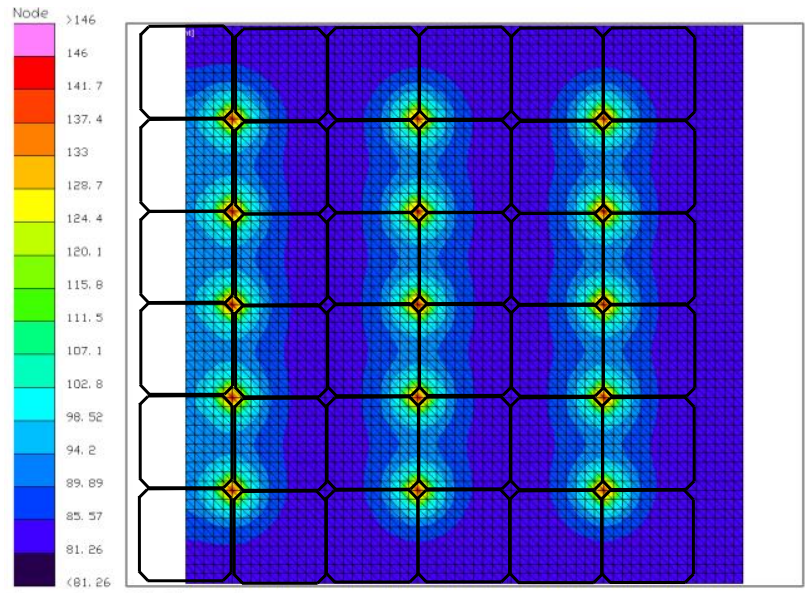

Fig. 10. Temperature distribution for 1 sun illumination on front-side and diode current $=1.0 \mathrm{~A}$ for the $58.3 \mathrm{~cm}^{2}$ cell. Color bar is in units of $\mathrm{C}$.

\section{SUMMARY}

The nominal design current for the SSL solar cell array is $1.0 \mathrm{~A}$. In the MSFC test with the ATJ cells $\left(30.5 \mathrm{~cm}^{2}\right)$, the maximum current achieved through the diodes while the diode temperature remained at $150 \mathrm{C}$ or below was $1.25 \mathrm{~A}$. For the case of diode current equal to $2.0 \mathrm{~A}$, temperatures $>250 \mathrm{C}$ were observed. The 1.25 A result indicates a $25 \%$ design margin. The MSFC test data were used for development of an SSL thermal model that was used for large solar cell designs (cell areas $\geq 55 \mathrm{~cm}^{2}$ ) where the operational current is $\sim 1.0 \mathrm{~A}$ at the one-Sun condition. A test coupon with the large solar cells has been fabricated and is undergoing qualification testing.

\section{REFERENCES}

[1] P. R. Sharps, M. A. Stan, D. J. Aiken, B. Clevenger, J. S. Hills, and N. S. Fatemi, "Multi-junction cells with monolithic bypass diodes", white paper, EMCORE Photovoltaics (now SolAero Technologies) 